\title{
Mechanisms involved in the $\beta$-cell mass increase induced by chronic sucrose feeding to normal rats
}

\author{
H Del Zotto, C L Gómez Dumm, S Drago ${ }^{1}$, A Fortino ${ }^{1}$, G C Luna \\ and J J Gagliardino
}

CENEXA, Centre of Experimental and Applied Endocrinology (UNLP-CONICET), University of La Plata School of Medicine, La Plata, Argentina
'Department of Biochemistry, University of Litoral, Santa Fe, Argentina
(Requests for offprints should be addressed to J J Gagliardino, CENEXA (UNLP-CONICET), Facultad de Ciencias Médicas, UNLP, Calle 60 y 120,1900 La Plata,
Argentina; Email: gagliardino@infovia.com.ar)

\begin{abstract}
The aim of the present study was to clarify the mechanisms by which a sucrose-rich diet (SRD) produces an increase in the pancreatic $\beta$-cell mass in the rat. Normal Wistar rats were fed for 30 weeks either an SRD (SRD rats; $63 \% \mathrm{wt} / \mathrm{wt}$ ), or the same diet but with starch instead of sucrose in the same proportion (CD rats). We studied body weight, serum glucose and triacylglycerol levels, endocrine tissue and $\beta$-cell mass, $\beta$-cell replication rate (proliferating cell nuclear antigen; PCNA), islet neogenesis (cytokeratin immunostaining) and $\beta$-cell apoptosis (propidium iodide). Body weight (g) recorded in the SRD rats was significantly $(P<0 \cdot 05)$ larger than that of the CD group $(556 \cdot 0 \pm 8 \cdot 3$ vs $470 \cdot 0 \pm 13 \cdot 1)$. Both serum glucose and triacylglycerol levels $(\mathrm{mmol} / \mathrm{l})$ were also significantly higher $(P<0.05)$ in SRD than in CD rats (serum glucose, $8 \cdot 11 \pm 0 \cdot 14$ vs $6 \cdot 62 \pm 0 \cdot 17$; triacylglycerol, $1.57 \pm 0 \cdot 18$ vs $0 \cdot 47 \pm 0 \cdot 04)$. The number of pancreatic islets per unit area
\end{abstract}

increased significantly $(P<0 \cdot 05)$ in SRD rats $(3 \cdot 29 \pm 0 \cdot 1$ vs $2 \cdot 01 \pm 0 \cdot 2)$. A significant increment $(2 \cdot 6$ times $)$ in the mass of endocrine tissue was detected in SRD animals, mainly due to an increase in the $\beta$-cell mass $(P=0 \cdot 0025)$. The islet cell replication rate, measured as the percentage of PCNA-labelled $\beta$ cells increased 6.8 times in SRD rats $(P<0 \cdot 03)$. The number of apoptotic cells in the endocrine pancreas decreased significantly (three times) in the SRD animals $(P=0 \cdot 03)$. The cytokeratin-positive area did not show significant differences between CD and SRD rats. The increase of $\beta$-cell mass induced by SRD was accomplished by an enhanced replication of $\beta$ cells together with a decrease in the rate of $\beta$-cell apoptosis, without any evident participation of islet neogenesis. This pancreatic reaction was unable to maintain serum glucose levels of these rats at the level measured in CD animals. Journal of Endocrinology (2002) 174, 225-231

\section{Introduction}

Prolonged administration of either a high fructose or sucrose diet to genetically selected rats induces a metabolic syndrome characterised by insulin resistance and decreased glucose tolerance, as well as increased plasma triglyceride and cholesterol levels (Cohen et al. 1977, Cohen 1978). We have previously reported that administration of a sucrose-rich diet (SRD) to normal rats for 6 months induced such metabolic abnormalities, together with a significant increase in both pancreatic islet number and $\beta$-cell area (Lombardo et al. 1996). These changes were accompanied by normal insulin plasma levels and pancreatic insulin content. However, the mechanisms by which the sucrose feeding produced the pancreatic morphological changes were not clear.

We have also found that sucrose administration to young normal hamsters results in time-dependent pancreatic changes, with increased $\beta$-cell mass caused by incremental $\beta$-cell replication and islet neogenesis, but keeping blood glucose levels within the normal range (Del Zotto et al. 1999). Administration of this diet to pregnant normal hamsters induced similar pancreatic changes in the newborn animals. However, these changes were of greater magnitude and were accompanied by a significant decrease in $\beta$-cell apoptosis together with a significant decrease in blood glucose levels (Gagliardino et al. 2000).

Normal pancreatic $\beta$-cell mass results from the final rate between two opposite processes: growth and destruction. Many experimental procedures lead to the stimulation of $\beta$-cell growth (Rosenberg et al. 1983, Bonner-Weir et al. 1989, Parsons et al. 1992, Wang et al. 1995, Lombardo et al. 1996). Among them, those obtained by modifying food intake are of especial interest for studying the pathophysiology of type 2 diabetes.

In order to clarify the mechanisms by which a high sucrose diet produces the above-mentioned pancreatic changes in the rat, we have studied $\beta$-cell replication rate, islet neogenesis and $\beta$-cell apoptosis in normal Wistar rats 
fed an SRD for 6 months. Our data showed that increased $\beta$-cell replication and decreased $\beta$-cell apoptosis could account for the increase in $\beta$ cells induced by SRD at this period.

\section{Materials and Methods}

\section{Animals and diets}

Normal male Wistar rats (180-200 g body weight; National Institute of Pharmacology, Buenos Aires, Argentina) were maintained in a temperature-controlled room $\left(23^{\circ} \mathrm{C}\right)$ with a fixed $12 \mathrm{~h}$ light: $12 \mathrm{~h}$ darkness cycle. They were initially fed standard rat laboratory chow (Ralston Purina, St Louis, MO, USA) to standardise the nutritional status. After 1 week, the rats were randomly divided into two groups: the experimental group received a semi-synthetic SRD (63\% wt/wt), while the control rats received the same semi-synthetic diet but with starch instead of sucrose in the same proportion (CD; 63\% wt/wt). Details of this procedure have been reported previously (Chicco et al. 1994). Both diets provide approximately $15.28 \mathrm{kj} / \mathrm{g}$ chow. The animals had free access to food and water and were maintained on their respective diets for a period of 30 weeks.

The weight of each animal was recorded twice per week, and the individual caloric intake and weight gain of at least ten animals in each group were assessed twice per week during the experimental period. On the day of the experiment, food was removed at $0900 \mathrm{~h}$, and experiments were performed between 0900 and $1200 \mathrm{~h}$. The experimental protocol was approved by the Human and Animal Research Committee of the School of Biochemistry, Universidad Nacional del Litoral, Santa Fe, Argentina.

\section{Blood parameters}

Rats were anaesthetised with an intraperitoneal injection of pentobarbital $(60 \mathrm{mg} / \mathrm{kg}$ body weight), and blood samples were drawn from the jugular vein and centrifuged at $4{ }^{\circ} \mathrm{C}$. The serum samples obtained were assayed either immediately or within the next 3 days after having been stored at $-20{ }^{\circ} \mathrm{C}$. Serum glucose (Bergmeyer 1974) and triacylglycerol (Laurell 1966) levels were determined by spectrophotometric methods.

\section{Immunohistochemical and morphometrical study of islets}

After removal of the whole pancreas, the fat tissue was carefully dissected away and the wet weight of the total gland recorded. Samples of the tail of the pancreas were then fixed in Bouin's fluid and embedded in paraffin, and serial sections $(5 \mu \mathrm{m})$ were obtained from different levels of the blocks. Haematoxylin-eosin staining was used for general structural observation. Each section from a given series was mounted on separate slides to stain adjacent sections for immunocytochemical identification of (1) insulin-secreting cells ( $\beta$ cells) and (2) glucagon-, somatostatin- and pancreatic polypeptide-secreting cells (non- $\beta$ cells). For this purpose, specimens were incubated with appropriate dilutions of (1) our own guinea pig anti-insulin serum (1:20000) and (2) a mixture of the other three rabbit antisera: antiglucagon (1:400), antipancreatic polypeptide $(1: 10000)$ (both kindly provided by Dr Lise Heding, Novo Nordisk, Copenhagen, Denmark) and anti-somatostatin (1:6000) (a gift from Dr Suad Efendic, Department of Endocrinology, Karolinska Institute, Copenhagen, Denmark). The reaction was completed using the streptavidin-biotin complex method, with either peroxidase or alkaline phosphatase together with carbazole and fast blue respectively as chromogens. Sections were counterstained with haematoxylin. Controls for serologic specificity were made by preincubating a given antiserum with an excess of the corresponding hormone for $24 \mathrm{~h}$ at $4{ }^{\circ} \mathrm{C}$. Morphometrical analysis was made by the point-counting method using an $8 \times 8 \mathrm{~mm}$ grid (256 squares and 289 intersections) mounted on the eyepiece of the microscope. To obtain the values of different parameters for $\beta$ and non- $\beta$ cells in the same section, we first processed the tissue for detection of $\beta$ cells by using anti-insulin serum, and then made the morphometrical measurements. In a second step, and on the top of the same section, we added the immunostain for detecting non- $\beta$ cells and made the measurement again. Values for non- $\beta$ cells resulted from the difference between both evaluations. Using this procedure, 11639 and 20314 insular cells were surveyed for the CD and SRD groups respectively.

With the data recorded, we calculated a unit area of total pancreas (15 872 intersections of the grid $=10 \mu \mathrm{m})$ excluding connective tissues. We were then able to obtain the area occupied by endocrine pancreas, exocrine pancreas, total pancreas, $\beta$ cells and non- $\beta$ cells, and several ratios and relationships as described in the Results. We also estimated the number of islets per unit area $\left(\mathrm{mm}^{2}\right)$. In addition, the ratio between islet cell area and the number of islet cells $(\beta$ and non- $\beta$ ) were calculated to obtain cell sizes. To estimate the islet and $\beta$-cell mass, we multiplied the respective volume density by the total weight of the pancreas (Bonner-Weir et al. 1989).

Every islet or small group of endocrine cells was recorded in each section, thus obtaining the number and areas of both $\beta$ and non- $\beta$ cells.

\section{$\beta$-cell apoptotic rate}

To identify apoptotic images, we used the propidium iodine technique (Scaglia et al. 1997). Deparaffinised and dehydrated sections were washed in phosphate-buffered saline (PBS) before incubation for $30 \mathrm{~min}$ in a dark humidified chamber with a solution of propidium iodine 
Table 1 Morphometrical analysis of pancreases from rats fed a sucrose-rich (SRD) or a control diet (CD) for 30 weeks. Values are the means \pm S.E.M. of four rat pancreases included in each group

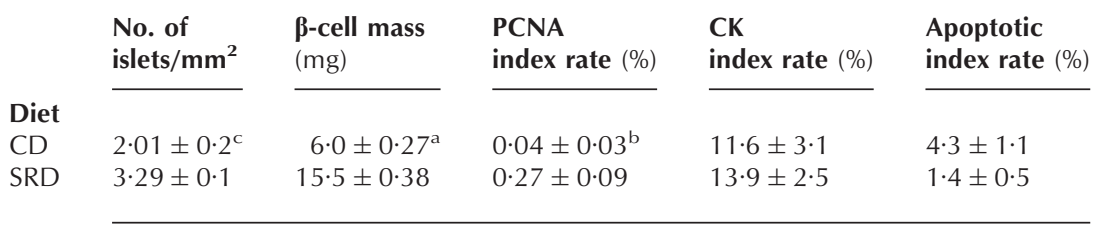

${ }^{\mathrm{a}} P<0 \cdot 0025 ;{ }^{\mathrm{b}} \mathrm{P}<0 \cdot 03 ;{ }^{\mathrm{c}} P<0 \cdot 05$.

(4 $\mu \mathrm{g} / \mathrm{ml}$; Sigma, St Louis, MO, USA) and ribonuclease A $(100 \mu \mathrm{g} / \mathrm{ml}$; Sigma). A Zeiss Axiolab epifluorescence microscope equipped with an HBO50 mercury lamp, together with two different filters, was used for visualisation of autofluorescent labelling. For the quantitative evaluation of immunofluorescence, positively labelled apoptotic endocrine cells were counted under a $\times 40$ objective lens in sections obtained from different levels of the blocks. The number of apoptotic cells was expressed as the percentage of the total islet cells counted.

\section{Cytokeratin immunostaining}

To reveal the presence of cytokeratin (CK)-positive cells, we used a specific monoclonal antibody for CK 19 (anti-CK clone 4.62; 1:40; Sigma) and the streptavidinbiotin complex method, with peroxidase and carbazole as chromogens. Before performing the staining, we treated deparaffinised sections with $250 \mathrm{ml}$ antigen-retrieval solution (Vector Laboratories Inc., Burlingame, CA, USA) for $10 \mathrm{~min}$ in a $500 \mathrm{~W}$ microwave oven (Madsen et al. 1997). The number of CK-positive cells is expressed as the percentage of the total islet cells counted.

\section{Islet cell replication rate: double-immunolabelling studies}

Islet cell replication rate was estimated by detecting proliferating cell nuclear antigen (PCNA; 1:4000; Sigma), using a modified avidin-biotin peroxidase method (Hsu et al. 1981). We quantified and expressed the replication rate as the percentage of PCNA-labelled cells among the total islet cells.

We followed two different procedures. (1) We performed double staining of the following pairs: $\beta$ (insulin antibody) and PCNA (PCNA antibody), and no $\beta$ (glucagon, somatostatin and pancreatic polypeptide pool) and PCNA. We then used the streptavidin-biotin complex method, with peroxidase and alkaline phosphatase together with carbazole and fast blue respectively as chromogens. Incubations with primary antibodies were overnight whereas those with the secondary biotinylated antibodies were for $30 \mathrm{~min}$. (2) For serial doubleimmunofluorescence labelling, sections pretreated with non-immune sera from rabbit diluted in Tris-buffered saline ( $\mathrm{pH} 7 \cdot 4)$ were incubated in a moist chamber at room temperature for $30 \mathrm{~min}$ with a solution of propidium iodine $(4 \mu \mathrm{g} / \mathrm{ml}$; Sigma) and ribonuclease A $(100 \mu \mathrm{g} / \mathrm{ml}$; Sigma) and for $1 \mathrm{~h}$ with glucagon antibody. After washing with PBS, fluorescence labelling of primary antibody was accomplished through a second incubation at room temperature for $45 \mathrm{~min}$ in the dark with the IgG-specific fluorescein-conjugated affinity-purified goat antibody against IgG (heavy plus light chains; Jackson Immuno Research Laboratories, Inc., Baltimore, MD, USA). After another washing with PBS, the sections were mounted in Tris-glycerol ( $\mathrm{pH} \mathrm{8.4)} \mathrm{for} \mathrm{analysis} \mathrm{by} \mathrm{fluorescence}$ microscopy.

\section{Statistical analysis}

Data are presented as means \pm S.E.M. Statistical analysis was performed using paired and unpaired Student's $t$-test. A $P$ value of $<0.05$ was considered significant.

\section{Results}

Body weight recorded in animals given the SRD (SRD rats) at the time of death was significantly higher than that of the CD group (556 \pm 8 vs $470 \pm 13 \mathrm{~g} ; P<0 \cdot 05)$. The pancreas weight did not show significant differences between CD and SRD rats $(1.56 \pm 0.07 \mathrm{mg}$ vs $1.62 \pm 0.04 \mathrm{mg}$ respectively). Both serum glucose and triacylglycerol levels $(\mathrm{mmol} / \mathrm{l})$ were significantly higher $(P<0.05)$ in SRD rats: glucose, $6.62 \pm 0.17$ for $\mathrm{CD}$ and $8 \cdot 11 \pm 0 \cdot 14$ for SRD; triacylglycerol, $0 \cdot 47 \pm 0 \cdot 04$ for CD and $1 \cdot 57 \pm 0 \cdot 18$ for SRD.

The sections stained with haematoxylin-eosin revealed the general histological pancreatic normal appearance both in CD and SRD rats. Immunohistochemistry showed the usual topographic distribution of the cells within the islets in both groups of animals, with the $\beta$ cells occupying the central zone and the non- $\beta$ cells located at the islet periphery.

Morphometrical analysis of the pancreases is shown in Table 1. The number of pancreatic islets per unit area increased significantly $(P<0 \cdot 05)$ in SRD rats compared with CD rats. Moreover, a significant increase was 

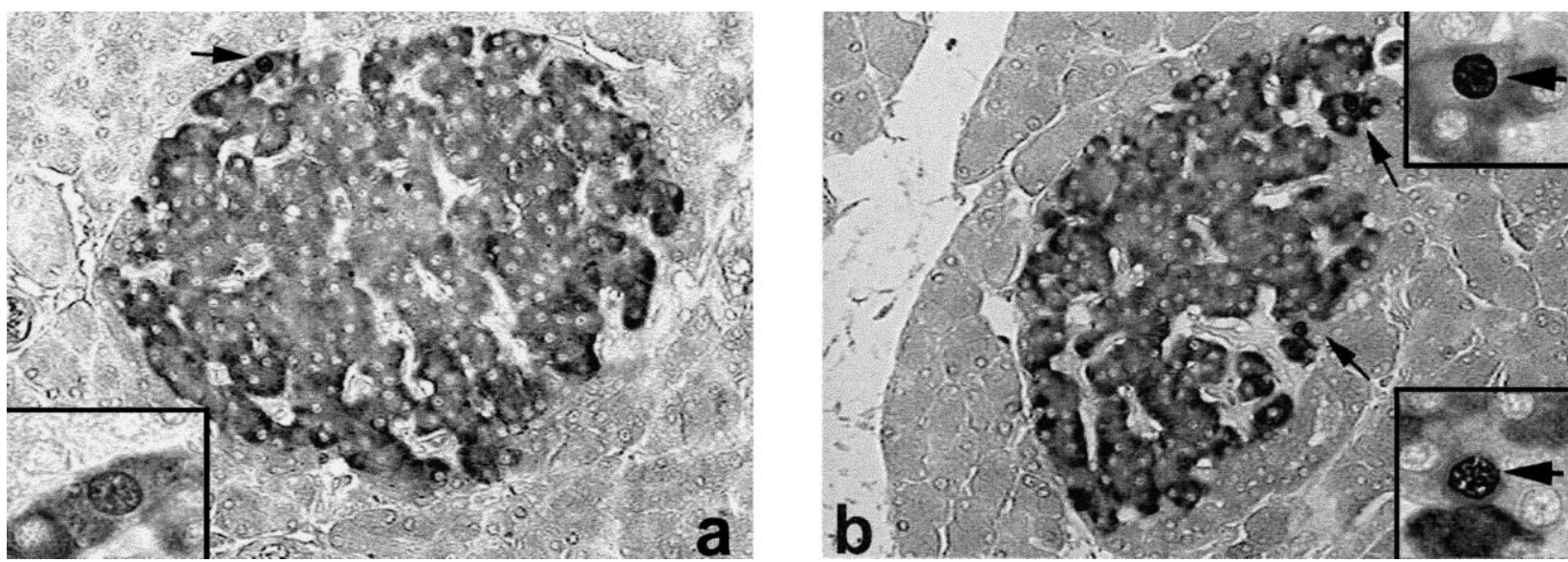

Figure 1 Double-immunolabelling pancreatic islets: nuclear proliferating cell nuclear antigen (PCNA) and cytoplasmic (insulin) stainings. The arrows point to positive-reacting cells, which are also seen at higher magnification (inserts). (a) Control (CD) and (b) sucrose-rich diet $(\mathrm{SRD})$ rats $(\times 200 ; \times 1000$ (inserts)).

observed in the mass of endocrine tissue of SRD animals. This increment was mainly due to an increase in the $\beta$-cell mass (2.6 times). The islet cell replication rate (Fig. 1), measured as the percentage of PCNA-labelled $\beta$ cells, increased 6.8 times in SRD rats. In addition, although the number of apoptotic cells was scarce in the endocrine pancreas, this number decreased significantly (three times) in the SRD animals (Fig. 2).

The CK immunostaining revealed positive-reacting endocrine cells always located at the islet periphery. The CK-positive area did not show significant differences between CD and SRD rats (Fig. 3). Other signs of neogenesis, such as a higher number of insulin-reacting cells in ductal epithelium together with an increase in their PCNA index, as well as a higher proportion of both small islets and islets in close contact with ducts were not found. The non- $\beta$-cell mass was also larger in the SRD group, although to a lesser extent with respect to the $\beta$-cell increase. On the other hand, the ratio between the islet cell area and the number of islet cells, which expresses the endocrine cell size, did not reveal significant differences; the values $\left(\mu \mathrm{m}^{2}\right)$ were as follows (CD vs SRD): $\beta$ cells, $121 \cdot 48 \pm 9 \cdot 73$ vs $118 \cdot 35 \pm 6 \cdot 46$; non $\beta$ cells, $97 \cdot 55 \pm 6 \cdot 24$ vs $95 \cdot 59 \pm 7 \cdot 05$.

\section{Discussion}

Our current results showed and confirmed those of Lombardo et al. (1996) that normal rats fed for 30 weeks with an SRD have a significant increase of both pancreatic islet and $\beta$-cell mass.

Chronic administration of glucose induces an insulinresistant state which represents an increased demand for
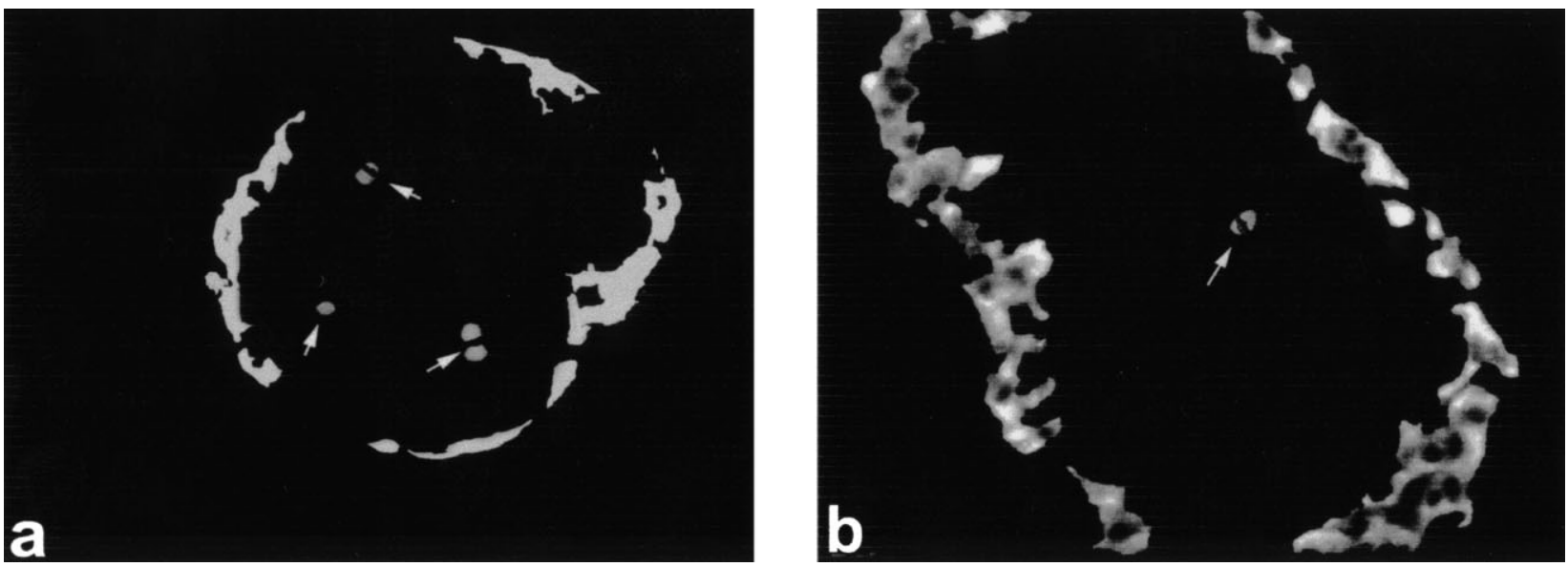

Figure 2 Pancreatic islets showing glucagon-positive cells in the periphery (immunofluorescence). Apoptotic nuclei (propidium iodine) corresponding to B cells are seen in the central zone (arrows). (a) CD rats and (b) SRD rats ( $\times 200)$. 


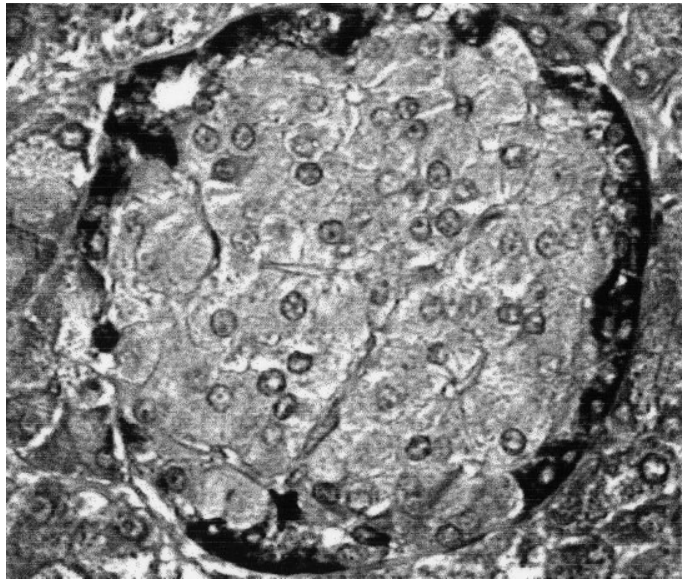

Figure 3 CK19-immunolabelled pancreatic islet from a CD rat. Positive-reacting non- $\beta$ cells are seen in the periphery; counterstained with haematoxylin $(\times 200)$.

insulin secretion that triggers changes in $\beta$-cell function (Leahy 1996). Pancreatic $\beta$-cell mass has to cope with insulin demand to keep serum glucose levels within normal range. Long-term adaptation of the $\beta$-cell mass to an increased demand results from an increase in the $\beta$-cell number through hyperplasia and neogenesis (Polonsky et al. 1998, Bonner-Weir 2000). However, $\beta$-cell expansion can be offset by concomitant apoptosis (Pick et al. 1998, Donath et al. 1999). In the present study, the increase of $\beta$-cell mass induced by SRD was accomplished by an enhanced replication of B cells (increased PCNA index rate) together with a decrease in the rate of $\beta$-cell apoptosis, without any evident signs (participation) of islet neogenesis. This pancreatic reaction was, however, unable to cope with the increased peripheral demand of insulin, since SRD animals exhibited higher serum glucose levels than did CD animals.

The moderate hyperglycaemia portrayed by our animals represents an additional challenge for the pancreatic $\beta$ cells since glucose can increase the replication of these cells, as occurs in both rats (Bonner-Weir 1989) and Psammomis obesus (Donath et al. 1999). However, hyperglycaemia can also adversely affect $\beta$-cell turnover in human islets (Maedler et al. 2001b).

Replication of pre-existing $\beta$ cells represents the main mechanism by which the normal adult increases the insulin-secreting active mass, although such a replication progressively decreases with ageing (Bonner Weir 2000, Montanya et al. 2000). Even when, during foetal and neonatal life, islets are newly formed from precursor cells that bud off from the pancreatic ducts (Swenne 1982, Hellerström 1984), only a low degree of neogenesis exists in the adult, this mechanism being enhanced under strong stimuli (Bonner-Weir 2000). CKs are considered good markers of the neogenetic area from which cells, originating in the ductal epithelium (protodifferentiated stem cells), are added to the islet mass (Bouwens et al. 1994, Wang et al. 1995). In the present study, CKs immunoreacted only with peripheral islet cells, probably non- $\beta$ cells, as was previously reported (Bouwens et al. 1994). Other signs of islet neogenesis, such as an increase in the replication rate and in the number of insulin-labelled cells at the ductal compartment, as well as an increment in the proportion of small islets and islets closely associated with ductal epithelium, were not evident in the pancreas of the SRD animals. Altogether, these observations suggest that neogenesis is not an important mechanism related to the islet mass increase currently observed.

The number of apoptotic cells significantly decreased when the rats received an SRD. Apoptosis is a morphologically identifiable form of cell death, triggered by a variety of metabolic stimuli, that plays an important role in remodelling the $\beta$-cell mass as the counterpart of proliferation (Wyllie et al. 1980, Steller 1995, Scaglia et al. 1997). Hoorens et al. (1996) postulated that the rat $\beta$ cells have a constitutive apoptotic programme that is blocked by proteins whose synthesis is stimulated by glucose in a dose-response manner. Thus, stimulation of such proteins triggered by SRD could account, at least partly, for the decreased apoptotic rate found in our experiments.

It has been reported that elevated glucose concentrations directly induce $\beta$-cell apoptosis in cultured islets from diabetes-prone P. obesus (Donath et al. 1999) and from normal humans (Federici et al. 2001), but an increase in glucose concentration to $11 \mathrm{mM}$ in rat islets promotes $\beta$-cell survival (Hoorens et al. 1996, Efanova et al. 1998, Donath et al. 1999, Maedler et al. 2001a). To explain this uneven behaviour, it has been argued that apoptosis induced by high glucose might involve Fas and upregulation of the Fas receptor (Maedler et al. 2001b), and that human islets constitutively express FasL, while islets from 2- to 3-month-old rats do not (Hanke 2000). Thus, differences in sensitivity to glucose may exist among species and also among individuals of the same species.

Sucrose administration to young hamsters for 5 weeks induces an increase in islet- and $\beta$-cell mass caused by incremented $\beta$-cell replication rate and islet neogenesis (Del Zotto et al. 1999). Even when the animals were kept on this diet for up to 24 weeks, they maintained their blood glucose levels within the normal range. A simultaneous increase of islet neogenesis-associated proteinpositive cell mass was also observed in these animals (Del Zotto et al. 2000), suggesting the participation of this peptide in the control of islet neogenesis.

Although sucrose administration to normal hamsters and rats triggered in both animals an increased $\beta$-cell mass, we found differences in the mechanisms leading to such an increase: neogenesis plus increased $\beta$-cell replication in the former and increased replication together with decreased apoptosis in the latter. When feeding hamsters for 24 weeks and rats for 30 weeks with an SRD, we found that the hamsters remained normoglycaemic while the rats 
showed a significant increase in serum glucose, as a result of the lack of a neogenic reaction. Thus, this reaction may play a key role in islets to satisfactorily adapt their $\beta$-cell mass to an increased demand of insulin. Additionally, we found that the ratio of $\beta$-cell mass:body weight is three times larger in hamsters than in rats (Del Zotto et al. 2000). This characteristic might also contribute to the more efficient pancreas reaction found in hamsters to the increased demand of insulin induced by SRD.

On the basis of the different capacity of pancreatic $\beta$-cell populations to cope with nutritionally increased insulin demand, Shafrir et al. (1999) have established two groups among models resembling type 2 diabetes. Those animals having a sturdy pancreas exhibit persistent hyperinsulinaemia, with an insulin resistance being compensated for by a good response of $\beta$ cells (anti-diabetic adaptation), while other animals have a brittle pancreas which cannot respond efficiently to the demands for a compensatory insulin release, and consequently develop a diabetic syndrome. According to our results, hamsters would belong to the first and rats to the second group postulated by Shafrir et al. (1999).

Our study shows, coincidentally with that previously reported (Leahy 1996), that diverse animal models can respond in a different manner under similar conditions to either $\beta$-cell function overload or hyperglycaemia. The pancreatic response to hyperglycaemia seems to be genetically determined; thus, the efficacy of the mechanisms that attempt to cope with similar experimental conditions will vary, rendering either a compensatory hyperinsulinaemicnormoglycaemic state or a diabetic state. Further studies using models similar to the one presently employed may help to find the underlying mechanisms that condition the uneven pancreatic compensatory response.

\section{Acknowledgements}

This study was partially supported by funds from CONICET and CICPBA of Argentina. Thanks are due to C Bianchi for helping with the immunohistochemistry and to E Gagliardino, A Di Maggio and G Simonetto for secretarial support.

\section{References}

Bergmeyer HU 1974 Determination with glucose oxidase and peroxidase. In Methods of Enzymatic Analysis, vol. 1-4, edn 2. New York: Academic Press.

Bonner-Weir S 2000 Islet growth and development in the adult. Journal of Molecular Endocrinology 85 2113-2115.

Bonner-Weir S, Deery D, Leahy JL \& Weir GC 1989 Compensatory growth of pancreatic B cells in adult rats after short-term glucose infusion. Diabetes 38 49-53.

Bouwens L, Wang RN, de Blay E, Pipeleers DG \& Klöppel G 1994 Cytokeratins as markers of ductal cell differentiation and islet neogenesis in the neonatal rat pancreas. Diabetes 43 1279-1283.
Chicco A, Soria A \& Fainstein-Day P 1994 Multiphasic metabolic changes in the heart of rats fed a sucrose-rich diet. Hormone and Metabolic Research 26 397-403.

Cohen AM 1978 Genetically determined response to different ingested carbohydrate in the production of diabetes. Hormone and Metabolic Research 10 86-92.

Cohen AM, Teitelbaum A \& Rosenman E 1977 Diabetes induced by high fructose diet. Metabolism 26 17-24.

Del Zotto H, Massa L, Gómez Dumm CL \& Gagliardino JJ 1999 Changes induced by sucrose administration upon the morphology and function of pancreatic islets in the normal hamster. Diabetes/Metabolism Research and Reviews 15 106-112.

Del Zotto H, Massa L, Rafaeloff R, Pittenger GL, Vinik A, Gold G, Reifel Miller A \& Gagliardino JJ 2000 Possible relationship between changes in islet neogenesis and islet neogenesis-associated protein-positive cell mass induced by sucrose administration to normal hamsters. Journal of Endocrinology 165 725-733.

Donath MY, Gross DJ, Cerasi E \& Kaiser N 1999 Hyperglycemiainduced B-cell apoptosis in pancreatic islets of Psammomis obesus during development of diabetes. Diabetes 48 738-744.

Efanova IB, Zaitsev SV, Zhivotovsky B, Kohler M, Efendic S, Orrenius S \& Berggren P-O 1998 Glucose and tolbutamide induce apoptosis in pancreatic beta-cells: a process dependent on intracellular $\mathrm{Ca}^{2+}$ concentration. Journal of Biological Chemistry 273 33501-33507.

Federici MH, Perego L, Ranalli M, Caradonna Z, Perego C, Usellini L, Nano R, Bonini P, Bertuzzi F, Marlier LNJL, Davalli AM, Carandente O, Pontirolo AE, Melino G, Marchetti P, Lauro R, Sesti G \& Folli F 2001. High glucose causes apoptosis in cultured human pancreatic islets of Langerhans. Diabetes 50 1290-1301.

Gagliardino JJ, Del Zotto H, Massa L, Reifel Miller A, Gold G \& Vinik A 2000 Simultaneous increase in B-cell and in Ingap-positive cell mass in offspring of sucrose-fed pregnant normal hamsters. Diabetes 49 A415.

Hanke J 2000 Apoptosis and occurrence of Bcl-2, Bak, Bax and Fas and FasL in the developing and adult rat endocrine pancreas. Anatomy and Embryology 202 303-312.

Hellerström C 1984 The life story of the pancreatic B cell. Diabetologia 26 393-400.

Hoorens A, Van de Casteele M, Kloppel G \& Pipeleers D 1996 Glucose promotes survival of rat pancreatic beta cells by activating synthesis of proteins which suppress a constitutive apoptotic program. Journal of Clinical Investigation 98 1568-1574.

Hsu SM, Raine L \& Fanger H 1981 Use of avidin-biotin-peroxidase complex $(\mathrm{ABC})$ in immunoperoxidase techniques: a comparison between $\mathrm{ABC}$ and unlabelled antibody (PAP) procedures. Journal of Histochemistry and Cytochemistry 29 577-580.

Laurell S 1966 A method for routine determination of plasma triglycerides. Scandinavian Journal of Clinical and Laboratory Investigation 18 668-672.

Leahy JL 1996 Impaired B-cell function with chronic hyperglycemia: 'Overworked B-cell' hypothesis. Diabetes Reviews 4 298-319.

Lombardo YB, Drago S, Chicco A, Fainstein-Day P, Gutman R, Gagliardino CL \& Gómez Dumm CLA 1996 Long-term administration of a sucrose-rich diet to normal rats: relationship between metabolic and hormonal profiles and morphological changes in the endocrine pancreas. Metabolism 45 1527-1532.

Madsen OD, Jensen J, Petersen HV, Peterson EE, Oster A, Andersen FG, Jorgensen MC, Yensen PB, Larsson LI \& Serup P 1997 Transcription factors contributing to the pancreatic beta-cell phenotype. Hormone and Metabolic Research 29 265-270.

Maedler K, Spinas GA, Dyntar D, Moritz W, Kaiser N \& Donath MY 2001a Distinct effect of saturated and monounsaturated fatty acids on B-cell turnover and function. Diabetes $\mathbf{5 0} 69-76$.

Maedler K, Spinas GA, Lehman R, Sergeev P, Weber M, Fontana A, Kaiser N \& Donath MY $2001 b$ Glucose induces B-cell apoptosis via upregulation of the Fas receptor in human islets. Diabetes $\mathbf{5 0}$ $1683-1690$ 
Montanya E, Nacher M, Biarnés M \& Soler J 2000 Linear correlation between $\beta$-cell mass and body weight throughout the lifespan in Lewis rats: role of $\beta$-cell hyperplasia and hypertrophy. Diabetes 49 1341-1346.

Parsons JA, Brelje TC \& Sorenson RL 1992 Adaptation of islets of Langerhans to pregnancy: increased islet cell proliferation and insulin secretion correlates with the onset of placental lactogen secretion. Endocrinology 130 1459-1466.

Pick A, Clark J, Kubstrup C, Levisetti M, Pugh W, Bonner-Weir S \& Polonsky KS 1998 Role of apoptosis in failure of B-cell mass compensation for insulin resistance and B-cell defects in the male Zucker diabetic fatty rat. Diabetes 47 358-364.

Polonsky KS, Sturis J \& Bell GI 1998 Seminars in Medicine of the Beth Israel Hospital, Boston: non-insulin-dependent diabetes mellitus: a genetically programmed failure of the beta cell to compensate for insulin resistance. New England Journal of Medicine $334777-783$

Rosenberg L, Brown RA \& Duguid WP 1983 A new approach to the induction of duct epithelial hyperplasia and nesidioblastosis by cellophane wrapping of the hamster pancreas. Journal of Surgical Research 35 632-672.
Scaglia L, Cahile CJ, Finegood DT \& Bonner-Weir S 1997 Apoptosis participates in the remodeling of the endocrine pancreas in the neonatal rat. Endocrinology 138 1736-1741.

Shafrir E, Ben-Sasson R \& Bar-On H 1999 Insulin resistance, B-cell survival, and apoptosis in type 2 diabetes: animal models and human implications. Diabetes Reviews 7 114-123.

Steller H 1995 Mechanisms and genes of cellular suicide. Science $\mathbf{2 6 7}$ 1445-1449.

Swenne I 1982 The role of glucose in vitro regulation of cell cycle kinetics and proliferation of fetal pancreatic B-cells. Diabetes 31 754-760.

Wang RN, Klöppel G \& Bouwens L 1995 Duct-to-islet cell differentiation and islet growth in the pancreas of duct ligated adult rats. Diabetologia 38 1405-1411.

Wyllie AH, Kerr JFR \& Currie AR 1980 Cell death: the significance of apoptosis. International Review of Cytology 68 251-306.

Received 4 January 2002

Accepted 10 April 2002 